Article

\title{
Hydrogen Bonding-Mediated Microphase Separation during the Formation of Mesoporous Novolac-Type Phenolic Resin Templated by the Triblock Copolymer, PEO-b-PPO-b-PEO
}

\author{
Wei-Cheng Chu, Shih-Fan Chiang, Jheng-Guang Li and Shiao-Wei Kuo* \\ Center for Nanoscience and Nanotechnology, Department of Materials and Optoelectronic Science, \\ National Sun Yat-Sen University, Kaohsiung 804, Taiwan
}

* Author to whom correspondence should be addressed; E-Mail: kuosw@faculty.nsysu.edu.tw; Tel.: +886-7-5252000 ext. 4079; Fax: +886-7-5254099.

Received: 16 September 2013; in revised form: 21 October 2013 / Accepted: 4 November 2013 / Published: 7 November 2013

\begin{abstract}
After blending the triblock copolymer, poly(ethylene oxide- $b$-propylene oxide- $b$-ethylene oxide) (PEO- $b$-PPO- $b$-PEO) with novolac-type phenolic resin, Fourier transform infrared spectroscopy revealed that the ether groups of the PEO block were stronger hydrogen bond acceptors for the $\mathrm{OH}$ groups of phenolic resin than were the ether groups of the PPO block. Thermal curing with hexamethylenetetramine as the curing agent resulted in the triblock copolymer being incorporated into the phenolic resin, forming a nanostructure through a mechanism involving reaction-induced microphase separation. Mild pyrolysis conditions led to the removal of the PEO- $b$-PPO- $b$-PEO triblock copolymer and formation of mesoporous phenolic resin. This approach provided a variety of composition-dependent nanostructures, including disordered wormlike, body-centered-cubic spherical and disorder micelles. The regular mesoporous novolac-type phenolic resin was formed only at a phenolic content of 40-60 wt \%, the result of an intriguing balance of hydrogen bonding interactions among the phenolic resin and the PEO and PPO segments of the triblock copolymer.
\end{abstract}

Keywords: hydrogen bonding; microphase separation; triblock copolymer; mesoporous structure; phenolic resin 


\section{Introduction}

Mesoporous materials having controllable pore sizes are attractive to both the academic and industrial communities, because of their various applications in the fields of filtering, separating, sensing, catalysis and controlled drug release [1-5]. The self-assembly of amphiphilic block copolymers as templates has been used extensively in the structure-directed syntheses of many mesoporous materials [5,6]. In the bulk state, block copolymers self-assemble into various nanostructures, including lamellae, gyroids, hexagonally packed cylinders, spheres and more complicated structures [7-10]. Many large-pores, long-range-ordered mesoporous silicates have been prepared using amphiphilic block copolymers as templates [11,12]. In addition to inorganic/organic assembly of mesoporous silicas, organic/organic self-assembly has also been used to synthesize ordered mesoporous or nanoporous polymeric materials from, for example, phenolic resin [13,14], polyurethane (PU) [15], polystyrene (PS) [16] and polyethylene (PE) [17].

The self-assembly of amphiphilic block copolymers into different thermoset polymers (e.g., phenolic and epoxy resins) has been used widely to prepare long-range-ordered nanostructures and mesopores [18-29]. For example, Ikkala and Ruokolainen et al. prepared long-range-ordered mesoporous phenolic resins from the diblock copolymers poly(isoprene- $b$-2-vinylpyridine) (PI- $b$-P2VP) and poly(styrene- $b$-4-vinylpyridine) (PS- $b$-P4VP) as templates, with hexamethylenetetramine (HMTA) as the curing agent [30-32]. Zheng et al. also reported the formation of long-range-ordered nanostructures in phenolic thermosets after curing novolac and the diblock copolymer poly(styrene- $b$-ethylene oxide) (PS- $b$-PEO) with HMTA [33]. From previous studies, we have also reported the formation of long-range-ordered cylinder and gyroid nanostructures of mesoporous phenolic resin templated by poly(ethylene oxide- $b$ - $\varepsilon$-caprolactone) (PEO- $b$-PCL) [11,12]. Long-range-ordered nanostructures can be formed after mixing uncured phenolic resins with block copolymers featuring a block that forms sufficiently strong hydrogen bonds with the phenolic $\mathrm{OH}$ groups, such that curing of the phenolic resin will preserve the self-assembled structure without undergoing macroscopic phase separation. In addition, controlled pyrolysis can be used subsequently to remove the structure-directing block copolymer template, leading to a monomodal mesoporous material featuring pores on a well-defined length scale [34-38]. The block copolymers used in those previous studies were, however, synthesized in the laboratory using complex and time-consuming techniques, such as anionic polymerization, atom transfer radical polymerization and ring opening polymerization [30-38]. Methods for modifying mesoporous structures employing commercial block copolymers would be simpler and more effective.

Recently, a family of ordered mesoporous carbon materials has been synthesized using poly(ethylene oxide)- $b$-poly(propylene oxide)- $b$-poly(ethylene oxide) (PEO-PPO-PEO) commercial triblock copolymers, such as F127 (EO $\left.\mathrm{EO}_{106} \mathrm{PO}_{70} \mathrm{EO}_{106}\right)$ and P123 $\left(\mathrm{EO}_{20} \mathrm{PO}_{70} \mathrm{EO}_{20}\right)$, as templates [39-42]. Resol-type phenolic resin precursors have often been used as the carbon source. Ikkala et al. reported the blending of resol-type phenolic resins with PEO-PPO-PEO triblock copolymers of three different molecular weights, namely $\mathrm{EO}_{8} \mathrm{PO}_{47} \mathrm{EO}_{8}, \mathrm{EO}_{17} \mathrm{PO}_{56} \mathrm{EO}_{17}$ and $\mathrm{EO}_{21} \mathrm{PO}_{47} \mathrm{EO}_{21}$ [43]; they observed only disordered micelle structures in these phenolic/block copolymer blends. Novolac, another popular type of phenolic resin, has been difficult to use in the preparation of ordered mesoporous polymers and carbons. Because novolac has a linear chain and thermoplastic properties, it melts when heated at high 
temperatures and, therefore, must be cured with HMTA to avoid collapsing during the pyrolysis stage [12]; accordingly, such materials exhibit poor periodicity (mostly worm-like or disordered micelle mesoporous structures). Zhao et al. have prepared mesoporous carbons using F127 and P123 as templates [39-42]. To date, however, the preparation of regular, ordered mesoporous novolac phenolic resins templated by PEO-PPO-PEO has remained a challenge. The phenolic $\mathrm{OH}$ groups of novolac should interact with the ether groups of both the PEO and PPO block segments of PEO-PPO-PEO, making it miscible at relatively higher phenolic resin contents. To prepare a phenolic resin exhibiting long-range order, the $\mathrm{OH}$ groups of the phenolic should interact with only the ether groups of PEO and not with those of PPO [44]. The triblock architecture might allow anchoring of the potentially repulsive PPO domains, if hydrogen bonding occurs only with the PEO domains. As a result, the length of the PEO blocks should be larger than that of the PPO blocks to ensure that the $\mathrm{OH}$ groups of the phenolic resin interact primarily with the ether units of the PEO blocks. The repulsive PPO block might lead to a phenolic resin exhibiting a long-range-ordered, self-assembled nanostructure.

In this study, we prepared regular, ordered mesoporous phenolic resins templated by the triblock copolymer, F127 $\left(\mathrm{EO}_{106} \mathrm{PO}_{70} \mathrm{EO}_{106}\right)$, because the PEO blocks were longer than those in the triblock copolymer, $\mathrm{P} 123\left(\mathrm{EO}_{20} \mathrm{PO}_{70} \mathrm{EO}_{20}\right)$. We had anticipated that the $\mathrm{OH}$ groups of the phenolic would form hydrogen bonds primarily with the ether groups of the PEO blocks at relative low phenolic resin content, but then would interact with the ether groups of the PPO block at relatively high phenolic resin content, possibly forming a variety of composition-dependent nanostructures (e.g., cylindrical, wormlike, spherical). Herein, we describe the phase behavior and hydrogen bonding interactions of phenolic nanostructures, which we investigated using differential scanning calorimetry (DSC), Fourier transform infrared (FTIR) spectroscopy, small-angle X-ray scattering (SAXS) and transmission electron microscopy (TEM).

\section{Results and Discussion}

\subsection{Thermal Analyses of Phenolic Resin/Block Copolymer Blends}

DSC is used extensively to investigate miscibility in polymer blends. The glass transition temperatures $\left(T_{\mathrm{g}}\right)$ of the pure polymers used in this study, phenolic, PEO and PPO, were $+64,-62$, and $-62{ }^{\circ} \mathrm{C}$, respectively. Figure 1 presents conventional second-run DSC thermograms of phenolic/F127 blends of various compositions (not cured with HMTA) obtained at a heating rate of $20{ }^{\circ} \mathrm{C} / \mathrm{min}$. In the region from -60 to $-75^{\circ} \mathrm{C}$, the pure $\mathrm{F} 127$ exhibited one glass transition at $-62{ }^{\circ} \mathrm{C}$, because the values of the $T_{\mathrm{g}}$ of PEO and PPO are very similar [45]. When blended with $30 \mathrm{wt} \%$ of phenolic resin, we observed two glass transitions at -62 and $-27^{\circ} \mathrm{C}$, indicating that phase separation had occurred at this blend composition. The higher value of $T_{\mathrm{g}}\left(-27^{\circ} \mathrm{C}\right)$ presumably arose from the phenolic/PEO phase formed through intermolecular hydrogen bonding between the $\mathrm{OH}$ groups of the phenolic resin and the ether groups of PEO; the lower value $\left(-62{ }^{\circ} \mathrm{C}\right)$ presumably arose from the PPO block segment. We would expect the inter-association equilibrium constant for phenolic/PEO to be larger than that for phenolic/PPO, based on extensive previous studies of the hydrogen bonding interactions of PEO and PPO [44,46-48]. Further increasing the phenolic resin content, the two glass transitions became a single one, with a shift toward higher temperature. A single value of $T_{\mathrm{g}}$ strongly suggests that these 
blends are fully miscible with a homogeneous amorphous phase. At relatively high contents of phenolic resin, the $\mathrm{OH}$ groups of the phenolic resin could interact with the ether groups of both the PEO and PPO block segments, thereby inducing total miscibility for the blend (disordered structure). Figure 2 reveals that a linear rule can be used to predict of the single values of $T_{\mathrm{g}}$ for the phenolic/F127 blend; these values are higher than those predicted using the Fox rule. This behavior is similar to that of the many ternary blends that become totally miscible when the content of a polymer presenting $\mathrm{OH}$ group is relatively high $[49,50]$.

Figure 1. Differential scanning calorimetry (DSC) thermograms of phenolic/F127 blends at various compositions.

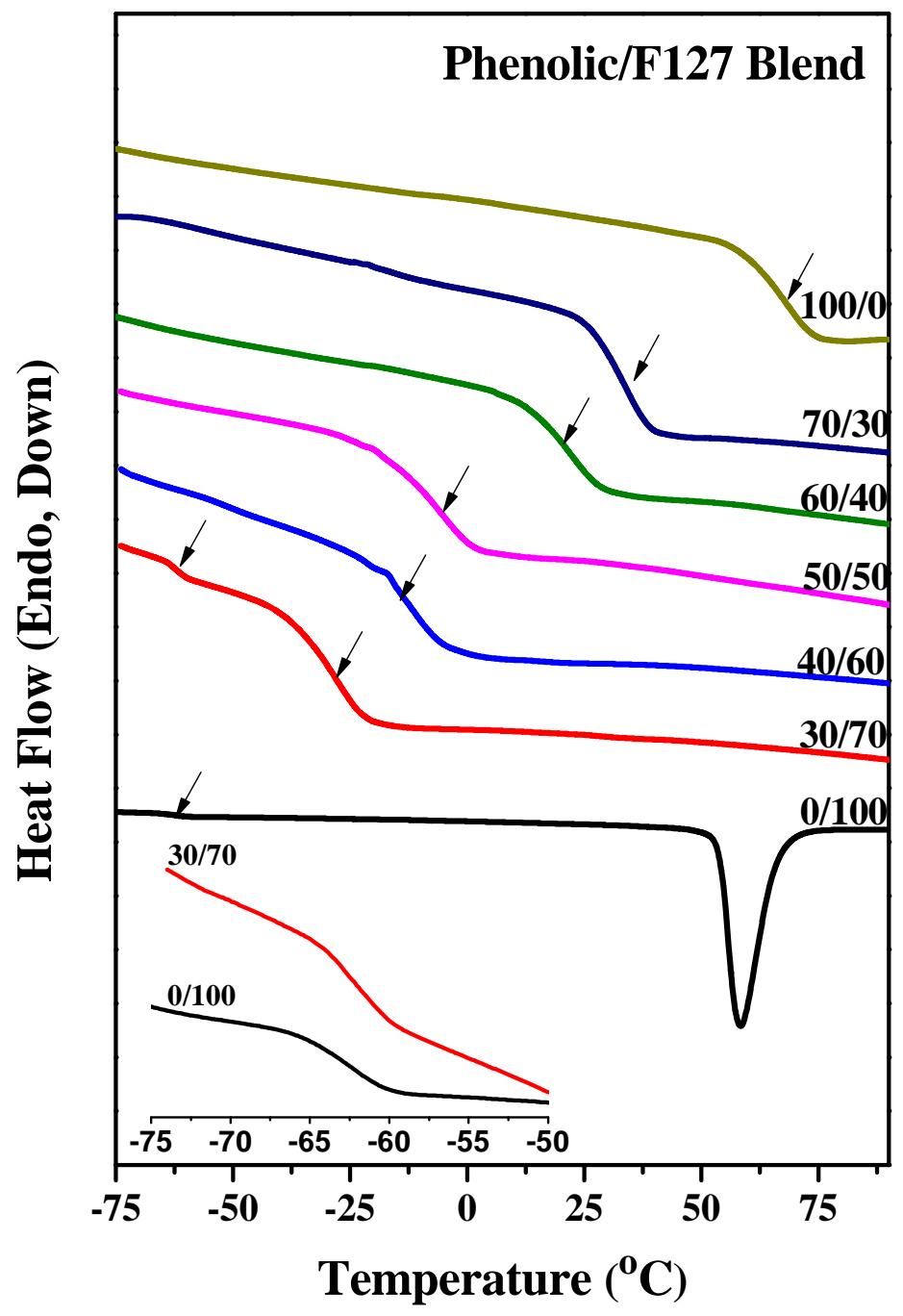


Figure 2. Glass transition $\left(T_{\mathrm{g}}\right)$ behavior of phenolic/F127 blends at various compositions.

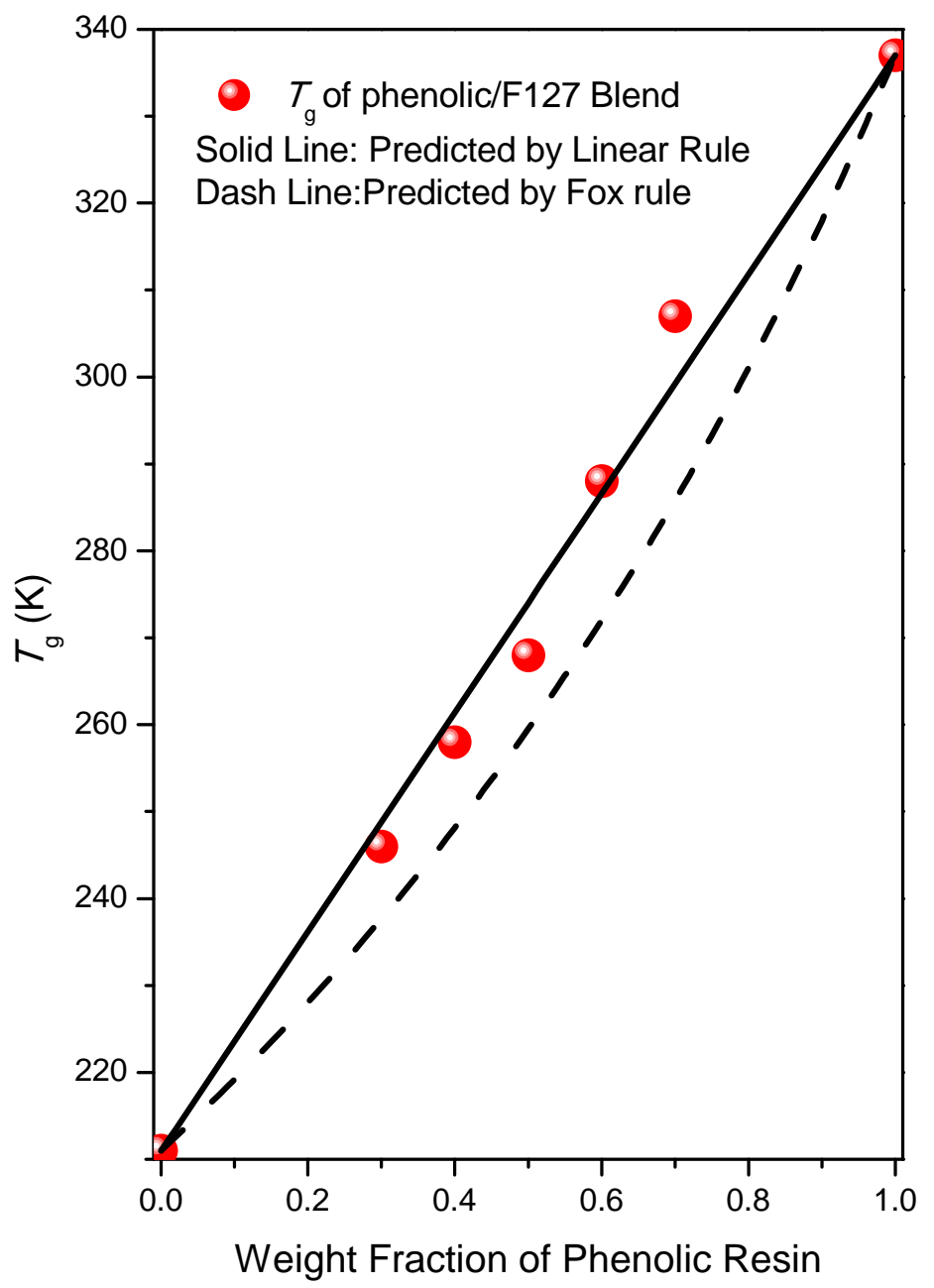

\subsection{FTIR Spectroscopic Analyses of Phenolic Resin/Block Copolymer Blends}

Infrared spectroscopy is a highly effective method for investigating hydrogen bonding interactions in polymer blend systems. Here, we used FTIR spectroscopy to provide evidence for hydrogen bonding within the phenolic/F127 blend. The signals in the $\mathrm{OH}$ stretching region of the room-temperature FTIR spectra for the blends of the F127 triblock and phenolic, cast from tetrahydrofuran solutions, were sensitive to the presence of hydrogen bonds (Figure 3a). The spectrum of phenolic resin featured two major unresolved bands in the $\mathrm{OH}$ stretching region, corresponding to the free $\mathrm{OH}$ groups at $3525 \mathrm{~cm}^{-1}$ and a broad band centered at $3360 \mathrm{~cm}^{-1}$ arising from the absorption of hydrogen-bonded $\mathrm{OH}$ groups (self-association). The intensity of the signal for the free $\mathrm{OH}$ groups decreased gradually upon increasing the content of the F127 triblock copolymer, as we had expected. The broad band of the phenolic resin at $3360 \mathrm{~cm}^{-1}$ became even broader when it was blended with F127 at higher phenolic contents, indicating that the $\mathrm{OH}$ groups of the phenolic interacted with the ether groups of both the PEO and PPO blocks. At lower phenolic contents, the signal for the $\mathrm{OH}$ groups involved in [OH $\cdots$ ether] hydrogen bonds with the PEO block appeared at a lower wavenumber of $3275 \mathrm{~cm}^{-1}$ [48], suggesting that the average hydrogen bonding strength followed the order $[\mathrm{OH} \cdots$ ether $]>[\mathrm{OH} \cdots \mathrm{OH}]$, consistent with the values of $T_{\mathrm{g}}$ being higher than those predicted using the Fox rule. 
Figure 3. FTIR spectra, recorded at room temperature, of phenolic/F127 blends at various compositions: (a) $\mathrm{O}-\mathrm{H}$ and $(\mathbf{b}) \mathrm{C}-\mathrm{O}-\mathrm{C}$ stretching regions.

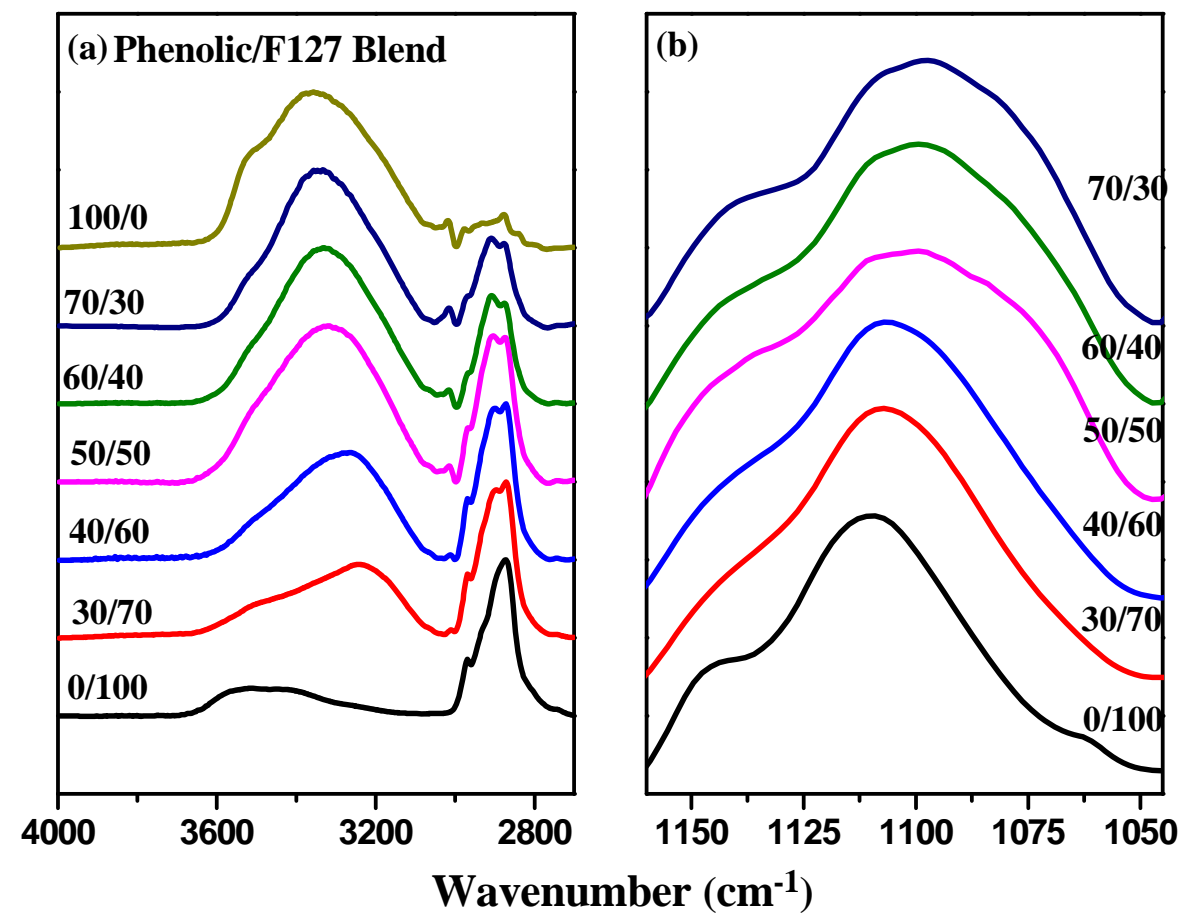

Figure $3 \mathrm{~b}$ displays the ether $\mathrm{C}-\mathrm{O}-\mathrm{C}$ stretching region of the phenolic/F127 blends at room temperature. According to a previous study, the free ether units of PPO and PEO provide bands near 1112 and $1104 \mathrm{~cm}^{-1}$, respectively; in addition, the signals for the ether groups of PPO and PEO hydrogen bonded to $\mathrm{OH}$ groups appear at 1090 and $1082 \mathrm{~cm}^{-1}$, respectively [44]. In this study, the signal for the ether units in the triblock copolymer, F127, was located at $1109 \mathrm{~cm}^{-1}$, corresponding to a combination of the free ether moieties of the PPO and PEO blocks. This peak shifted to a lower wavenumber upon increasing the content of phenolic resin. When an ether forms a hydrogen bond with a phenolic resin, the lone pair of electrons on the oxygen atom are withdrawn by the $\mathrm{OH}$ group of the phenolic, thereby decreasing the electron density from the ether $\mathrm{C}-\mathrm{O}$ bonds and inducing a shift in the band to a lower wavenumber. The main ether peak at $1109 \mathrm{~cm}^{-1}$ shifted to $1106 \mathrm{~cm}^{-1}$ at a phenolic resin content of 30 and $40 \mathrm{wt} \%$, to $1100 \mathrm{~cm}^{-1}$ at $50 \mathrm{wt} \%$ and to $1098 \mathrm{~cm}^{-1}$ at 60 and $70 \mathrm{wt} \%$. In addition, a shoulder appeared at $1074 \mathrm{~cm}^{-1}$ at relatively higher phenolic resin contents; this signal corresponded to the ether units of the PPO block hydrogen bonded with the phenolic resin.

\subsection{Thermal Analyses of Phenolic Resin/Block Copolymer Blends with HMTA Curing}

Next, we investigated the thermal behavior of the phenolic/F127 blends prepared with HMTA as a curing agent. Prior to thermal curing, all of our binary mixtures of the phenolic and F127 were homogenous and transparent. After thermal curing, the phenolic resin remained homogenous and transparent, but became dark red in color, suggesting that macrophase separation had not occurred. Nevertheless, we could not explain reaction-induced microphase separation merely in terms of sample clarity. Figure 4a presents conventional second-run DSC thermograms of phenolic/F127 blends with HMTA at various compositions, recorded at a heating rate of $20{ }^{\circ} \mathrm{C} / \mathrm{min}$. The blends exhibited a 
melting temperature that corresponded to that of crystalline PEO. Meanwhile, both the pure F127 and phenolic/F127 = 30/70 with HMTA curing exhibited two strong diffraction peaks at 17.29 and 21.04, arising from the crystal structure of the PEO blocks (Figure 4b) [36]. Prior to thermal curing, the phenolic/F127 blend featured the amorphous phase of PEO and PPO at a phenolic resin content of 30 wt \%; it became a crystalline phase after thermal curing with HMTA, due to a mechanism based on reaction-induced phase separation, which is caused by the increase in the average molar mass of the polymer superimposed by possible variations of the interaction parameter with thermal curing. Further increasing the content of phenolic resin caused all of the systems to become amorphous, without melting temperature (DSC), consistent with the wide-angle X-ray diffraction analyses. Furthermore, the glass transition of the PPO block segment was observed at $-62{ }^{\circ} \mathrm{C}$ for phenolic/F $127=40 / 60$ with HMTA thermal curing; this signal was not apparent in the absence of HMTA thermal curing. Clearly, microphase separation occurred in the cured blends of the phenolic thermosets with F127, possibly through reaction-induced demixing from homogenous mixtures.

Figure 4. (a) DSC thermograms and (b) wide-angle X-ray diffraction analyses of phenolic/F127 blends with hexamethylenetetramine (HMTA) curing. PEO, poly(ethylene oxide).
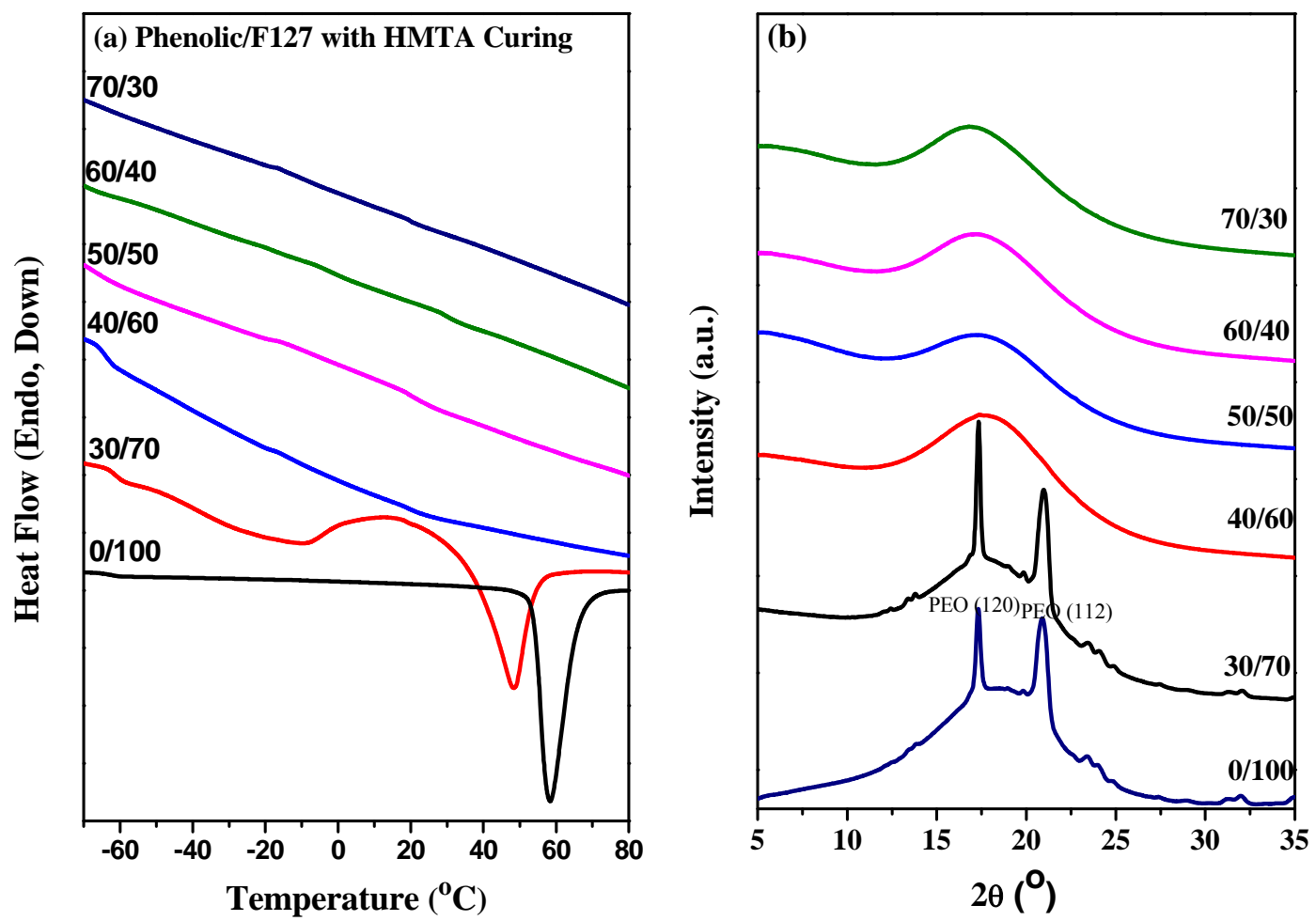

Figure 5 displays thermogravimetric analyses, under an atmosphere of air, of the phenolic/F127 blends with HMTA thermal curing. Pure F127 underwent its main degradation at a temperature near $230{ }^{\circ} \mathrm{C}$ (Figure $5 \mathrm{a}$ ). At a phenolic content of $50 \mathrm{wt} \%$, this thermal degradation temperature increased to $350{ }^{\circ} \mathrm{C}$ at a heating rate of $20^{\circ} \mathrm{C} / \mathrm{min}$ (Figure $5 \mathrm{c}$ ), and at a phenolic content of $30 \mathrm{wt} \%$, this thermal degradation temperature also increased to $380{ }^{\circ} \mathrm{C}$ at a heating rate of $20{ }^{\circ} \mathrm{C} / \mathrm{min}$ (Figure $5 \mathrm{~d}$ ). If we selected a heating rate of $2{ }^{\circ} \mathrm{C} / \mathrm{min}$, however, the $\mathrm{F} 127$ readily decomposed at $330{ }^{\circ} \mathrm{C}$, as it did after isothermal treatment for $3 \mathrm{~h}$ at $330{ }^{\circ} \mathrm{C}$ (Figure $5 \mathrm{~b}$ ). This result implied that the F127 template could be removed readily through pyrolysis in air, leaving behind the phenolic resin. 
Figure 5. TGA analyses of (a) the pure triblock copolymer, F127, at a heating rate of $20{ }^{\circ} \mathrm{C} / \mathrm{min}$; (b) phenolic/F127 $=50 / 50$ with HMTA thermal curing at a heating rate of $2{ }^{\circ} \mathrm{C} / \mathrm{min}$ and after isothermal treatment for $3 \mathrm{~h}$; (c) phenolic/F127 = 50/50 with HMTA thermal curing at a heating rate of $20^{\circ} \mathrm{C} / \mathrm{min}$; and (d) phenolic/F127 $=30 / 70$ with HMTA thermal curing at a heating rate of $20^{\circ} \mathrm{C} / \mathrm{min}$.

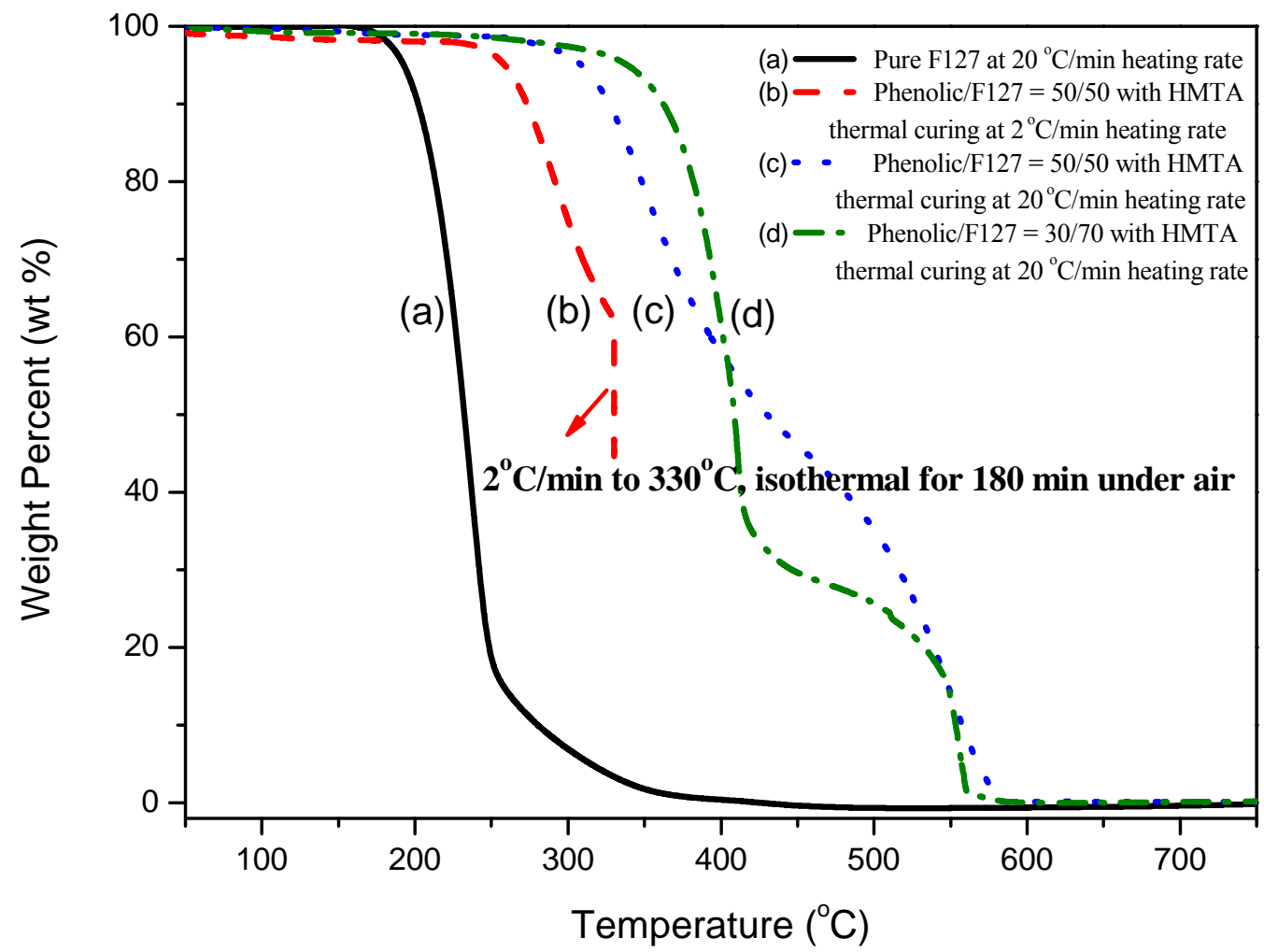

\subsection{SAXS, TEM and BET Analyses of Mesoporous Phenolic Resins}

We recorded SAXS profiles of the mesoporous phenolic resins templated by the triblock copolymer, F127, at room temperature to confirm their self-organized mesoporous morphologies. Figure 6 reveals that the phenolic content influenced the formation of the mesostructures. In the SAXS profiles of the mesoporous phenolic resins templated by F127 (Figure 6a), we observe a broad peak corresponding to the disordered mesoporous phenolic resin formed at a relatively low phenolic content (30 wt \%), consistent with the TEM image in Figure 6b. The blend prepared with a phenolic content of $40 \mathrm{wt} \%$ provided a single broad peak at a value of $q^{*}$ of approximately $0.54 \mathrm{~nm}^{-1}(d=11.62 \mathrm{~nm})$ with second-order reflections at $3^{1 / 2} q^{*}$ (see inset) that correspond to the short-range order of a hexagonally packed cylinder structure; this result is consistent with the TEM image in Figure 6c, which displays a worm-like structure. The SAXS pattern of the blend with $50 \mathrm{wt} \%$ phenolic resin exhibits a strong and narrow scattering peak at a value of $q$ of $0.56 \mathrm{~nm}^{-1}(d=11.21 \mathrm{~nm})$. The higher-order peaks are clearly evident at $2^{1 / 2}: 3^{1 / 2}: 4^{1 / 2}: 5^{1 / 2} q^{*}$, corresponding to a body-centered-cubic spherical structure, consistent with the TEM image in Figure 6d. When the phenolic content was $60 \mathrm{wt} \%$, the SAXS pattern featured only a single broad peak at a value of $q^{*}$ of approximately $0.52 \mathrm{~nm}^{-1}(d=12.07 \mathrm{~nm})$, due to incomplete disordering of the mesoporous micellar structure at this composition; the TEM image in Figure 6e reveals a disordered mesoporous micellar structure for this sample, similar to that previously 
reported for a phenolic/PS- $b-\mathrm{P} 4 \mathrm{VP}=70 / 30$ system [30]. Further increasing the phenolic resin content to $70 \mathrm{wt} \%$ resulted in a disordered structure, based on the appearance of broad peaks in the SAXS pattern, indicating the absence of long-range order in the structure; the TEM image confirmed this result (Figure 6f).

Figure 6. (a) Small-angle X-ray scattering (SAXS) patterns and (b-f) transmission electron microscopy images of mesoporous phenolic templated by F127 at phenolic/F127 ratios of (b) 30/70; (c) 40/60; (d) 50/50; (e) 60/40 and (f) 70/30.

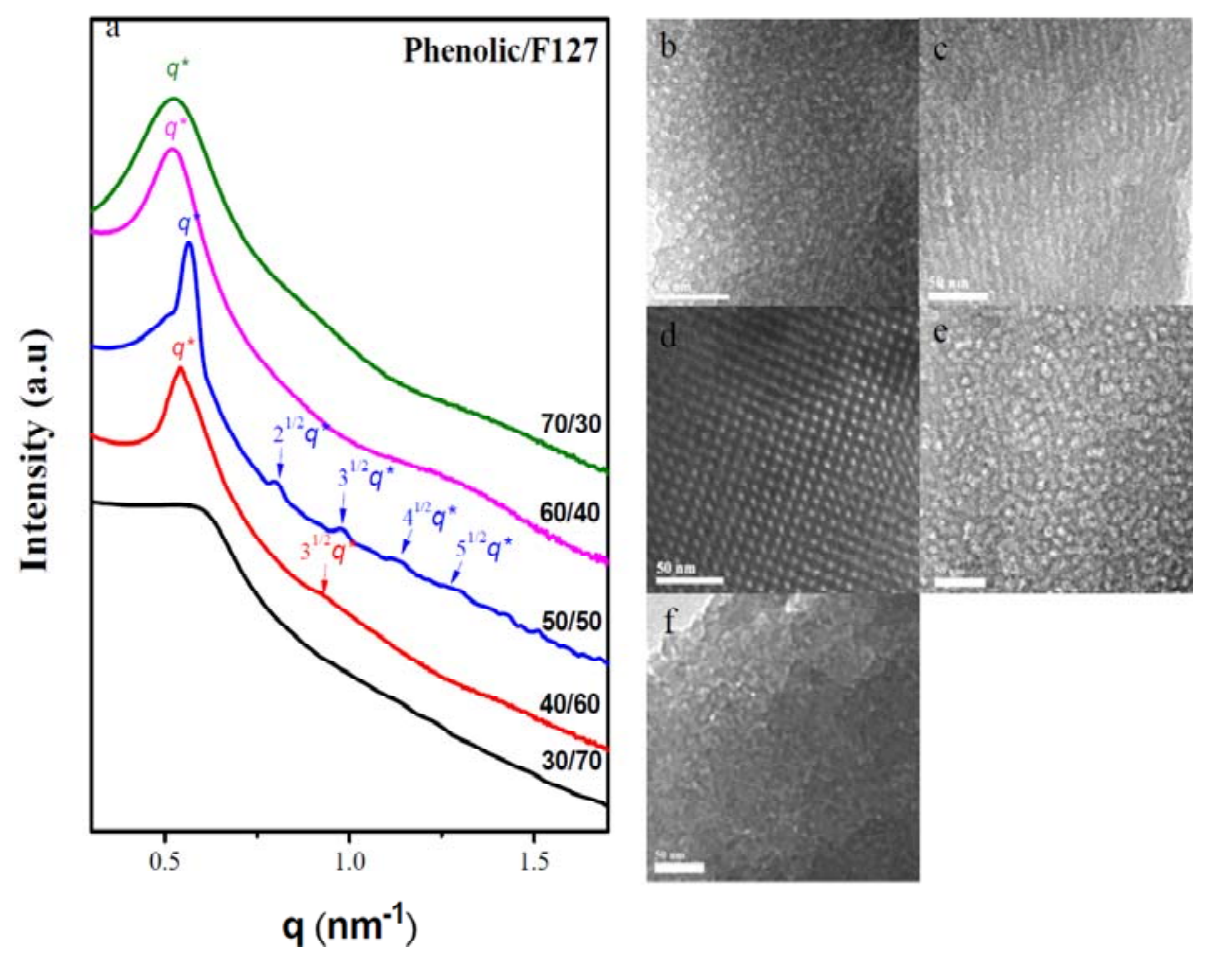

Therefore, the key factor for preparing mesoporous phenolic structures templated by the triblock copolymer, F127, is that the phenolic $\mathrm{OH}$ groups should form hydrogen bonds with the ether units of the PPO block, but the fraction of hydrogen-bonded PPO ether moieties should not be so high that a miscible disorder system forms. As a result, the regular mesoporous phenolic resin that forms, templated by the triblock copolymer, F127, is strongly dependent on the phenolic resin content. Scheme 1 summarizes the mechanism of the formation of mesoporous phenolic resins templated by the triblock copolymer, F127. At lower phenolic contents $(<30 \mathrm{wt} \%$ phenolic), the system contained insufficient phenolic resin relative to the template F127, forming a disordered structure (Scheme 1a). At higher phenolic content (>70 wt \% phenolic; Scheme 1e), a completely miscible disordered structure formed, because the phenolic $\mathrm{OH}$ groups formed hydrogen bonds with both the PEO and PPO blocks, according to FTIR spectroscopy. As a result, the self-organized mesoporous phenolic resin formed only at phenolic contents of 40-60 wt \%, through an intriguing balance of the interactions of phenolic, PEO and PPO (Scheme 1b-d). Most importantly, we have developed a simple evaporation-induced self-assembly (EISA) method for the synthesis of new mesoporous phenolic resin having a $b c c$ structure when applying the copolymer, F127, having a large volume fraction of its EO block segments, as the template at phenolic/F127 =50/50 (Scheme 1d). Figure 7 summarized the data from the SAXS, TEM and Brunauer-Emmett-Teller (BET) analyses. The SAXS pattern of this 
bcc-type mesoporous phenolic resin exhibited (Figure 7a) a strong reflection with a large $d$-spacing of $11.21 \mathrm{~nm}$ and another four strong reflections at values of $q$ of $0.79,0.97,1.12$ and $1.25 \mathrm{~nm}^{-1}$; this SAXS pattern could be indexed as having (110), (200), (211), (220) and (310) reflections, corresponding to a cubic structure (Im $\overline{3} m$ space group). In addition, we confirmed the structural ordering and cubic symmetry of this material through TEM analyses.

Scheme 1. Morphologies of mesoporous phenolic resins templated by F127 at various compositions.

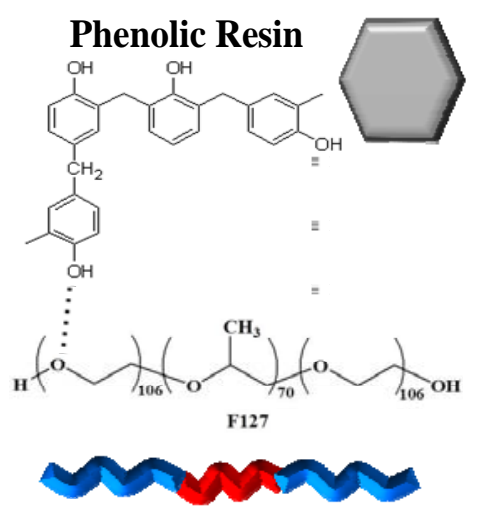

Triblock Copolymer

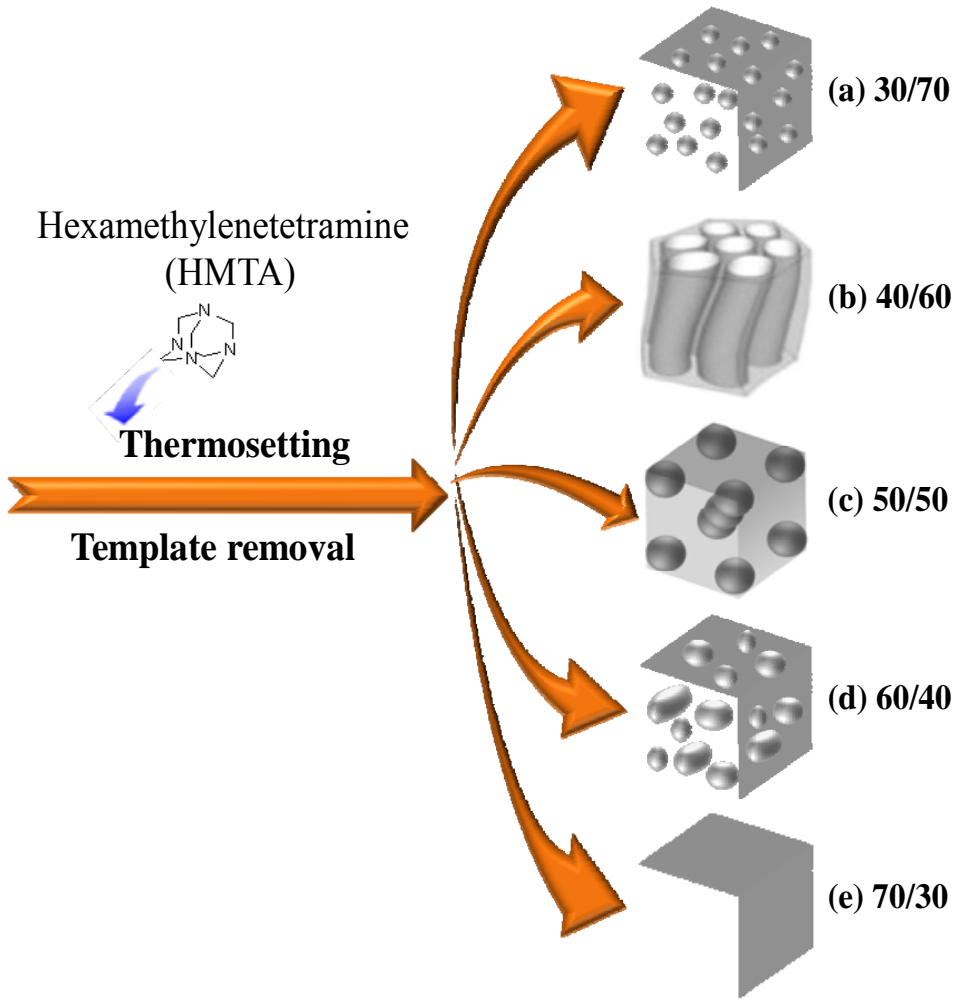

Figure 7b-d display TEM images of the bcc-type mesoporous phenolic resin with different orientations ((100), (110) and (111) planes, respectively), consistent with a three-dimensional (3D) cubic cage structure having a large $d$-spacing - a material having potential advantages when applied in catalysis and separation. Notably, these synthesis conditions enabled the facile and highly reproducible preparation of a large-cage 3D cubic mesoporous phenolic resin having $\operatorname{Im} \overline{3} m$ symmetry. We obtained further information regarding the textural properties of the materials from $\mathrm{N}_{2}$ adsorption/desorption isotherms measured at $77 \mathrm{~K}$. Figure 7 e presents the $\mathrm{N}_{2}$ sorption isotherms of the cubic mesoporous phenolic resin sample. The sample displays individual type-IV isotherms, exhibiting an apparent $\mathrm{H}_{2}$ hysteresis loop characteristic of a cage-like mesoporous material. A sharp capillary condensation step appeared for this sample, suggesting uniform pore dimensions and high-quality ordering of the materials, in agreement with the TEM and SAXS data. Pore size distribution analysis revealed (Figure 7f) a well-ordered cubic structure having pores with an average diameter of approximately $4.8 \mathrm{~nm}$. The significant width of the hysteresis loops also observed for the Santa-Barbara-16 (SBA-16) and Fudan University-16 (FDU-16) samples studied herein suggested cage-like pore shapes [51,52]. 
Figure 7. (a) SAXS pattern; (b-d) TEM images viewed from (b) (110); (c) (100) and (d) (111) (insets: corresponding Fast Fourier transform); (e) $\mathrm{N}_{2}$ adsorption/desorption isotherm and (f) pore size distribution curve of the $b c c$ mesoporous phenolic templated by F127 at a phenolic resin content of $50 \mathrm{wt} \%$.
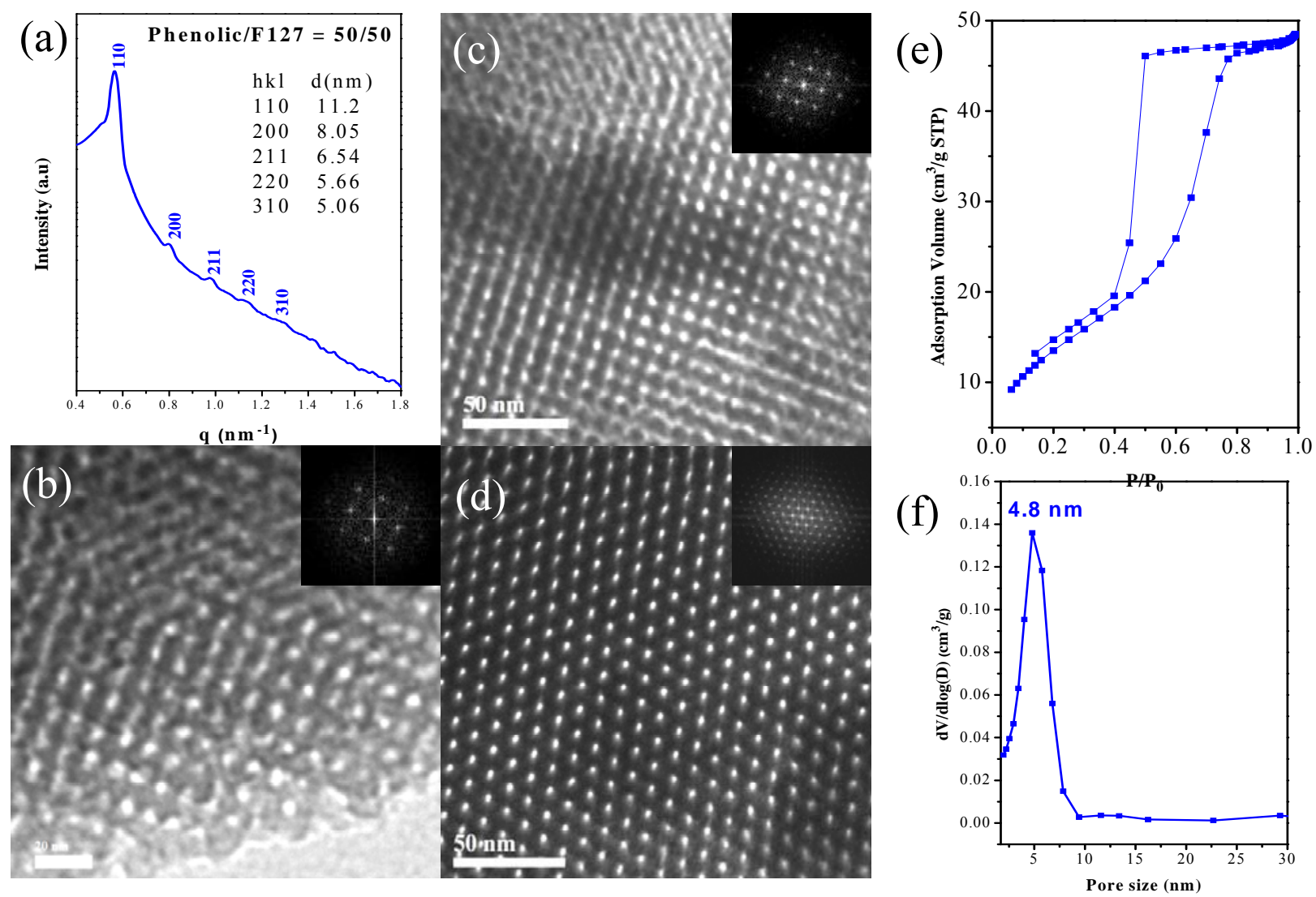

Figure 8 a summarizes the $\mathrm{N}_{2}$-sorption phys-isotherm of other mesoporous phenolic resins templated by the triblock copolymer, F127. The mesoporous phenolic samples templated by F127 triblock copolymers at phenolic contents of 30,40,50 and $60 \mathrm{wt} \%$ exhibited representative type-IV curves. We did not, however, find such a curve at a phenolic content of $70 \mathrm{wt} \%$, indicating that no mesoporous structure formed at this composition. The hysteresis loops gradually changed from $\mathrm{H}_{1}$-type loops at phenolic contents of 30 and $40 \mathrm{wt} \%$ to an $\mathrm{H}_{2}$-type loop at a phenolic content of $50 \mathrm{wt} \%$. Because an $\mathrm{H}_{1}$-like hysteresis loop is usually attributed to uniformly branched and cylindrical pores, such a change in the feature of the hysteresis loops may reflect a change in the mesoporous structure from a cylinder to $b c c$ structure. Based on the model of Harkins and Jura [53], the mean pore sizes measured from the adsorption branch for mesoporous phenolic resins prepared at phenolic contents of 30, 40, 50 and $60 \mathrm{wt} \%$ were $4.8,5.5,4.8$ and $5.8 \mathrm{~nm}$, respectively. Table 1 summarizes the BET surface areas, pore volumes and Barrett-Joyner-Halenda BJH pore sizes of our mesoporous phenolic materials. The total BET surface area and the total pore volume decreased upon increasing the phenolic content of the templating triblock copolymer, F127. The low BET surface areas in this study may come presumably from partial collapse of the well-defined structure during pyrolysis. To the best of our knowledge, this study is the first in which a long-range-ordered, bcc-type, mesoporous, novolac-type phenolic resin has been fabricated using an EISA strategy. 
Figure 8. (a) $\mathrm{N}_{2}$ adsorption/desorption isotherms and (b) pore size distribution curves of mesoporous phenolic templated by F127 at phenolic/F127 weight fractions of 30/70, 40/60, $50 / 50,60 / 40$ and $70 / 30$.
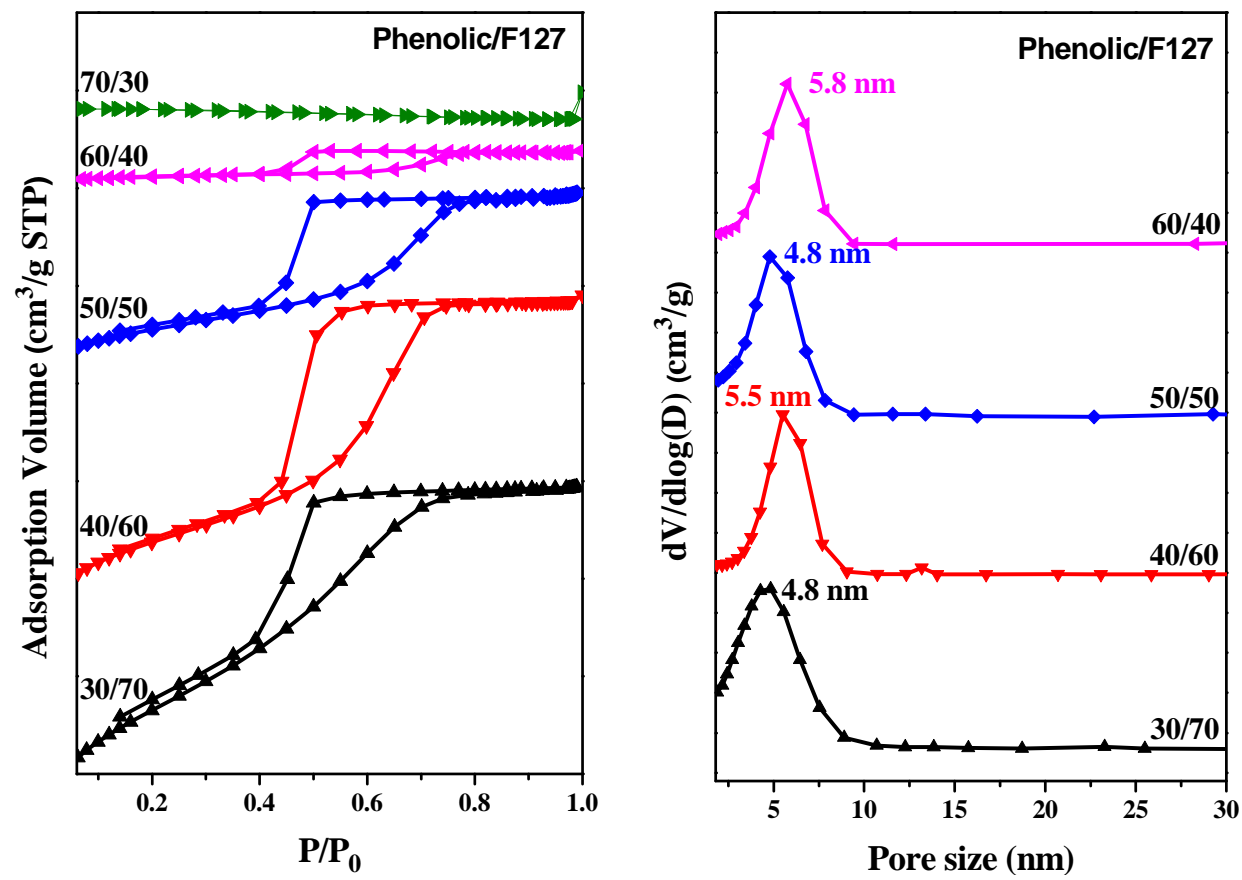

Table 1. Textural properties of mesoporous phenolic resins templated by F127.

\begin{tabular}{ccccc}
\hline Sample Phenolic/F127 & $\boldsymbol{d}(\mathbf{n m})^{\mathbf{a}}$ & Pore Size $(\mathbf{n m})$ & $\boldsymbol{S}_{\text {BET }}\left(\mathbf{m}^{2} / \mathbf{g}\right)$ & Pore Volume $\left(\mathbf{c m}^{\mathbf{b}} / \mathbf{g}\right)$ \\
\hline $30 / 70$ & 10.6 & 4.8 & 155 & 0.15 \\
$40 / 60$ & 11.6 & 5.5 & 82 & 0.11 \\
$50 / 50$ & 11.2 & 4.8 & 52 & 0.08 \\
$60 / 40$ & 12.1 & 5.8 & 10 & 0.01 \\
$70 / 30$ & 12.1 & - & - & - \\
\hline
\end{tabular}

${ }^{\mathrm{a}}$ The $d$-spacing was calculated from the first SAXS peak, using the formula $d=2 \pi / q^{*}$; ${ }^{\mathrm{b}}$ Total Brunauer-Emmett-Teller (BET) surface area.

\section{Experimental Section}

\subsection{Materials}

The triblock copolymer, Pluronic F127 $\left(\mathrm{EO}_{106} \mathrm{PO}_{70} \mathrm{EO}_{106} ; M_{\mathrm{n}}=12,600\right)$, was purchased from Aldrich (St. Louis, MO, USA). The phenolic resin was synthesized through a condensation reaction mediated by sulfuric acid, resulting in an average molecular weight $\left(M_{\mathrm{n}}=500\right)$ similar to those described previously [54,55].

\subsection{Phenolic/F127 Blends}

Phenolic resin and Pluronic F127 were dissolved in THF and stirred for 30 min to form a homogeneous solution. The sample was poured onto an aluminum plate, and then, the THF was slowly evaporated at room temperature for 3 days; the sample was subsequently vacuum-dried at $30{ }^{\circ} \mathrm{C}$ for $24 \mathrm{~h}$. 


\subsection{Mesoporous Phenolic Resins}

Phenolic resin, HMTA and Pluronic F127 were dissolved in THF and stirred for $30 \mathrm{~min}$ to form a homogeneous solution. The sample was poured onto an aluminum plate, and then, the THF was slowly evaporated at room temperature for 3 days; the sample was subsequently vacuum-dried at $30{ }^{\circ} \mathrm{C}$ for $24 \mathrm{~h}$. Curing of the sample was performed using the following temperature profile: $100{ }^{\circ} \mathrm{C}$ for $2 \mathrm{~h}$, $150{ }^{\circ} \mathrm{C}$ for $2 \mathrm{~h}$ and $190{ }^{\circ} \mathrm{C}$ for $2 \mathrm{~h}$. Pyrolysis of the cross-linked sample was performed by calcinating at $330{ }^{\circ} \mathrm{C}$ for $3 \mathrm{~h}$ in the absence of a protective gas atmosphere. Calcination was conducted in a furnace operated at a heating rate of $2{ }^{\circ} \mathrm{C} / \mathrm{min}$.

\subsection{Characterization}

Thermal analysis was performed using a Q-20 differential scanning calorimeter (TA Instruments Q-20, New Castle, DE, USA) operated at a heating rate of $20{ }^{\circ} \mathrm{C}$ and a cooling rate of $5{ }^{\circ} \mathrm{C} / \mathrm{min}$ from +150 to $-90{ }^{\circ} \mathrm{C}$ under $\mathrm{N}_{2}$; the sample weighed between 5 and $10 \mathrm{mg}$. The thermal stability of the samples was characterized using a TA Q-50 Thermogravimetric Analyzer TA Instruments (New Castle, DE, USA) operated under $\mathrm{N}_{2}$ or air; the sample ( $c a .7 \mathrm{mg}$ ) was placed in a Pt cell and heated at a rate of $20{ }^{\circ} \mathrm{C} / \mathrm{min}$ from 30 to $800{ }^{\circ} \mathrm{C}$ at a $\mathrm{N}_{2}$ flow rate of $60 \mathrm{~mL} / \mathrm{min}$ or at $1.4{ }^{\circ} \mathrm{C} / \mathrm{min}$ to $330{ }^{\circ} \mathrm{C}$ and then held isothermally for $180 \mathrm{~min}$ at an air flow rate of $60 \mathrm{~mL} / \mathrm{min}$. FTIR spectra of the samples were recorded with a Nicolet Avatar 320 FTIR spectrometer (Thermo Scientific, Waltham, MA, USA) and the conventional $\mathrm{KBr}$ disk method. SAXS experiments were performed using the small/wide angle X-ray scattering (SWAXS) instrument at the BL23A1 beamline of the National Synchrotron Radiation Research Center, (NSRRC), Taiwan; the X-ray beam had a diameter of $0.5 \mathrm{~mm}$ and a wavelength $(\lambda)$ of $1.24 \AA$; the $d$-spacings were calculated using the formula $d=2 \pi / q$, where $q$ is the scattering vector. TEM images were recorded using a JEOL 2100 microscope (Tokyo, Japan) operated at $200 \mathrm{kV}$; samples for TEM measurement were suspended in ethanol and supported onto a holey carbon film on a $\mathrm{Cu}$ grid. Nitrogen adsorption/desorption isotherms were measured at $-196{ }^{\circ} \mathrm{C}$ using an accelerated surface area and porosimetry system (ASAP) 2020 analyzer (Micromeritics, GA, USA); prior to measurements, the samples were degassed under vacuum at $200{ }^{\circ} \mathrm{C}$ for at least $6 \mathrm{~h}$. The Brunauer-Emmett-Teller (BET) method was employed to calculate the specific surface areas; using the Broekhoff-de Boer (BdB) sphere model, the pore volumes and pore size distributions were derived from the adsorption branches of the isotherms; the total pore volumes were estimated from the amounts adsorbed at a relative pressure $\left(P / P_{0}\right)$ of 0.995 .

\section{Conclusions}

We have employed DSC, TEM, SAXS and FTIR spectroscopy to investigate the miscibility, phase behavior and hydrogen bonding within phenolic/F127 triblock copolymer blends. DSC and FTIR spectroscopy provided evidence for the ether units of the PEO and PPO blocks being hydrogen bond acceptors for the $\mathrm{OH}$ groups of the phenolic resin. SAXS and TEM analyses indicated that phenolic/F127 blends of different compositions resulted in different microphase-separated structures, mediated through hydrogen bonding interactions. Most importantly, we report the first examples of mesoporous novolac-type phenolic resins formed after mild pyrolysis of the templating triblock 
copolymer, F127. The mesoporous phenolic resins exhibited a long-range-ordered bcc structure only when the phenolic content was $50 \mathrm{wt} \%$, formed through a mechanism involving an intriguing balance of interactions among the phenolic and the components of the block copolymer.

\section{Acknowledgments}

This study was supported financially by the National Science Council, Taiwan, under contracts National Science Council (NSC) 100-2221-E-110-029-MY3 and NSC 102-2221-E-110-008-MY3. We thank Hsien-Tsan Lin of the Regional Instruments Center at National Sun Yat-Sen University for helping with the TEM experiments.

\section{Conflicts of Interest}

The authors declare no conflict of interest.

\section{References}

1. Corma, A. From microporous to mesoporous molecular sieve materials and their use in catalysis. Chem. Rev. 1997, 97, 2373-2420.

2. Ariga, K.; Vinu, A.; Ji, O.; OOhmori, O.; Hill, J.P.; Acharya, S.; Koike, J.; Shiratori, S. A layered mesoporous carbon sensor based on nanopore-filling cooperative adsorption in the liquid phase. Angew. Chem. Int. Ed. 2008, 47, 7254-7257.

3. Vallet-Regi, M.; Balas, F.; Acros, D. Mesoporous materials for drug delivery. Angew. Chem. Int. Ed. 2007, 46, 7548-7558.

4. Zhao, J.; Gao, F.; Fu, Y.; Jin, W.; Yang, P.; Zhao, D. Biomolecule separation using large pore mesoporous SBA-15 as a substrate in high performance liquid chromatography. Chem. Commun. 2002, 752-753.

5. Jo, E.; Lim, M.C.; Kim, H.N.; Park, H.J.; Kim, Y.R.; Jeong, U. Microfluidic channels fabricated on mesoporous electrospun fiber mats: A facile route to microfluidic chips. J. Polym. Sci. Polym. Phys. 2011, 49, 89-95.

6. Zhao, D.; Feng, J.; Huo, Q.; Melosh, N.; Fredrickson, G.H.; Chmelka, B.F.; Stucky, G.D. Triblock copolymer syntheses of mesoporous silica with periodic 50 to 300 angstrom pores. Science 1998, 279, 548-552.

7. Rodriguez-Hernandez, J.; Checot, F.; Gnanou, Y.; Lecommandoux, S. Toward "smart" nano-objects by self-assembly of block copolymers in solution. Prog. Polym. Sci. 2005, 30, 691-724.

8. Hamley, I.U. The Physics of Block Copolymers; Oxford University Press: Oxford, UK, 1998.

9. Foerster, S.; Antonietti, M. Amphiphilic block copolymers in structure-controlled nanomaterial hybrids. Adv. Mater. 1998, 10, 195-217.

10. Hadjichristidis, N.; Pispas, S.; Floudas, G.A. Block Copolymers Synthetic Strategies, Physical Properties, and Applications; John Wiley\& Sons: Hoboken, NJ, USA, 2003.

11. Li, J.G.; Kuo, S.W. Phase behavior of mesoporous nanostructures templated by amphiphilic crystalline-crystalline diblock copolymers of poly(ethylene oxide- $b$ - $\varepsilon$-caprolactone). RSC $A d v$. 2011, 1, 1822-1833. 
12. Li, J.G.; Lin, Y.D.; Kuo, S.W. From microphase separation to self-organized mesoporous phenolic resin through competitive hydrogen bonding with double crystalline diblock copolymers of poly(ethylene oxide- $b$ - $\varepsilon$-caprolactone). Macromolecules 2011, 44, 9295-9309.

13. Gorka, J.; Zawislak, A.; Choma, J.; Jaroniec, M. KOH activation of mesoporous carbons obtained by soft-templating. Carbon 2008, 46, 1159-1161.

14. Song, L.; Feng, D.; Fredin, N.J.; Yager, K.G.; Jones, R.L.; Wu, Q.; Zhao, D.; Vogt, B.D. Challenges in fabrication of mesoporous carbon films with ordered cylindrical pores via phenolic oligomer self-assembly with triblock copolymers. ACS Nano 2010, 4, 189-198.

15. Gao, C.; Hu, X.; Hong, Y.; Guan, J.; Shen, J. Photografting of poly(hydroxylethyl acrylate) onto porous polyurethane scaffolds to improve their endothelial cell compatibility. J. Biomater. Sci. Polym. Ed. 2003, 14, 937-950.

16. Zalusky, A.S.; Olayo-Valles, R.; Taylor, C.J.; Hillmyer, M.A. Mesoporous polystyrene monoliths. J. Am. Chem. Soc. 2001, 123, 1519-1520.

17. Pitet, L.M.; Amendt, M.A.; Hillmyer, M.A. Nanoporous linear polyethylene from a block polymer precursor. J. Am. Chem. Soc. 2010, 132, 8230-8231.

18. Hillmyer, M.A.; Lipic, P.M.; Hajduk, D.A.; Almdal, K.; Bates, F.S. Self-assembly and polymerization of epoxy resin-amphiphilic block copolymer nanocomposites. J. Am. Chem. Soc. 1997, 119, 2749-2750.

19. Lipic, P.M.; Bates, F.S.; Hillmyer, M.A. Nanostructured thermosets from self-assembled amphiphilic block copolymer/epoxy resin mixtures. J. Am. Chem. Soc. 1998, 120, 8963-8970.

20. Guo, Q.; Thomann, R.; Gronski, W. Phase behavior, crystallization, and hierarchical nanostructures in self-organized thermoset blends of epoxy resin and amphiphilic poly(ethylene oxide)-block-poly(propylene oxide)-block-poly(ethylene oxide) triblock copolymers. Macromolecules 2002, 35, 3133-3144.

21. Meng, F.; Zheng, S.; Li, H.; Liang, Q.; Liu, T. Formation of ordered nanostructures in epoxy thermosets: A mechanism of reaction-induced microphase separation. Macromolecules 2006, 39, 5072-5080.

22. Muylaert, I.; Verberckmoes, A.; Decker, J.D.; Voort, P.V.D. Ordered mesoporous phenolic resins: Highly versatile and ultra stable support materials. Adv. Colloid Interface Sci. 2012, 175, 39-51.

23. Tanaka, S.; Nishiyama, N.; Egashira, Y.; Ueyama, K. Synthesis of ordered mesoporous carbons with channel structure from an organic-organic nanocomposite. Chem. Commun. 2005, 2125-2127.

24. Maiez-Tribut, S.; Pascault, J.P.; Soule, E.R.; Borrajo, J.; Williams, R.J.J. Nanostructured epoxies based on the self-assembly of block copolymers: A new miscible block that can be tailored to different epoxy formulations. Macromolecules 2007, 40, 1268-1273.

25. Xu, Z.; Zheng, S. Reaction-induced microphase separation in epoxy thermosets containing poly(E-caprolactone)-block-poly(n-butyl acrylate) diblock copolymer. Macromolecules 2007, 40, 2548-2558.

26. Ritzenthaler, S.; Court, F.; David, I.; Girard-Reydet, E.; Leibler, I.; Pascault, J.P. ABC triblock copolymers/epoxy-diamine blends. 1. keys to achieve nanostructured thermosets. Macromolecules 2002, 35, 6245-6254. 
27. Fan, W.; Wang, L.; Zheng, S. Nanostructures in thermosetting blends of epoxy resin with polydimethylsiloxane-block-poly(e-caprolactone)-block-polystyrene $\mathrm{ABC}$ triblock copolymer. Macromolecules 2009, 42, 327-336.

28. Meng, F.; Xu, Z.; Zheng, S. Microphase separation in thermosetting blends of epoxy resin and poly(E-caprolactone)-block-polystyrene block copolymers. Macromolecules 2008, 41, 1411-1420.

29. Mijovic, J.; Shen, M.; Sy, J.W. Dynamics and morphology in nanostructured thermoset network/block copolymer blends during network formation. Macromolecules 2000, 33, 5235-5244.

30. Kosonen, H.; Ruokolainen, J.; Nyholm, P.; Ikkala, O. Self-organized cross-linked phenolic thermosets: Thermal and dynamic mechanical properties of novolac/block copolymer blends. Polymer 2001, 42, 9481-9486.

31. Kosonen, H.; Ruokolainen, J.; Nyholm, P.; Ikkala, O. Self-organized thermosets: Blends of hexamethyltetramine cured novolac with poly(2-vinylpyridine)-block-poly(isoprene). Macromolecules 2001, 34, 3046-3049.

32. Valkama, S.; Nykanen, A.; Kosonen, H.; Ramani, R.; Tuomisto, F.; Engelhardt, P.; ten Brinke, G.; Ikkala, O.; Ruokolainen, J. Hierarchical porosity in self-assembled polymers: Post-modification of block copolymer-phenolic resin complexes by pyrolysis allows the control of micro- and mesoporosity. Adv. Funct. Mater. 2007, 17, 183-190.

33. Hu, D.; Xu, Z.; Zeng, K.; Zheng, S. From self-organized novolac resins to ordered nanoporous carbons. Macromolecules 2010, 43, 2960-2969.

34. Li, J.G.; Chung, C.Y.; Kuo, S.W. Transformations and enhanced long-range ordering of mesoporous phenolic resin templated by poly(ethylene oxide-b-e-caprolactone) block copolymers blended with star poly(ethylene oxide)-functionalized silsesquioxane (POSS). J. Mater. Chem. 2012, 22, 18583-18595.

35. Li, J.G.; Chang, Y.H.; Lin, Y.S.; Kuo, S.W. Templating amphiphilic poly(ethylene oxide- $b$ - $\varepsilon$-caprolactone) diblock copolymers provides ordered mesoporous silicas with large tunable pores. RSC Adv. 2012, 2, 12973-12982.

36. Chu, W.C.; Li, J.G.; Kuo, S.W. From flexible to mesoporous polybenzoxazine resins templated by poly(ethylene oxide- $b$ - $\varepsilon$-caprolactone) copolymer through reaction induced microphase separation mechanism. RSC Adv. 2013, 3, 6485-6498.

37. Li, J.G.; Chu, W.C.; Jeng, U.S.; Kuo, S.W. In situ monitoring of the reaction-induced self-assembly of phenolic resin templated by diblock copolymers. Macromol. Chem. Phys. 2013, 214, 2115-2123.

38. Kosonen, H.; Valkama, S.; Nykänen, A.; Toivanen, M.; ten Brinke, G.; Ruokolainen, J.; Ikkala, O. Functional porous structures based on the pyrolysis of cured templates of block copolymer and phenolic resin. Adv. Mater. 2006, 18, 201-205.

39. Deng, Y.; Liu, C.; Yu, T.; Liu, F.; Zhang, F.; Wan, Y.; Zhang, L.; Wang, C.; Tu, B.; Webley, P.A.; Wang, H.; Zhao, D. Facile synthesis of hierarchically porous carbons from dual colloidal crystal/block copolymer template approach. Chem. Mater. 2007, 19, 3271-3277.

40. Yan, Y.; Zhang, F.; Meng, Y.; Tu, B.; Zhao, D. One-step synthesis of ordered mesoporous carbonaceous spheres by an aerosol-assisted self-assembly. Chem. Commun. 2007, 2867-2869.

41. Huang, Y.; Cai, H.; Feng, D.; Gu, D.; Deng, Y.; Tu, B.; Wang, H.; Webley, P.A.; Zhao, D. One-step hydrothermal synthesis of ordered mesostructured carbonaceous monoliths with hierarchical porosities. Chem. Commun. 2008, 2641-2643. 
42. Huang, Y.; Yang, J.; Cai, H.; Zhai, Y.; Feng, D.; Deng, Y.; Tu, B.; Zhao, D. A curing agent method to synthesize ordered mesoporous carbons from linear novolac phenolic resin polymers. J. Mater. Chem. 2009, 19, 6536-6541.

43. Kosonen, H.; Ruokolainen, J.; Torkkeli, M.; Serimaa, R.; Nyholm, P.; Ikkala, O. Micro- and macrophase separation in phenolic resol resin/PEO-PPO-PEO block copolymer blends: Effect of hydrogen-bonded PEO length. Macromol. Chem. Phys. 2002, 203, 388-392.

44. Serman, C.J.; Xu, Y.; Painter, P.C.; Coleman, M.M. Poly(vinyl phenol)—polyether blends. Polymer 1991, 32, 516-522.

45. Kulinski, Z.; Piorkowska, E.; Gadzinowska, K.; Stasiak, M. Plasticization of Poly(L-lactide) with Poly(propylene glycol). Biomacromolecules 2006, 7, 2128-2135.

46. Chen, S.; Guo, C.; Liu, H.Z.; Wang, J.; Liang, X.F.; Zheng, L.; Ma, J.H. Thermodynamic analysis of micellization in PEO-PPO-PEO block copolymer solutions from the hydrogen bonding point of view. Mol. Simul. 2006, 32, 409-418.

47. Kuo, S.W. Hydrogen-bonding in polymer blends. J. Polym. Res. 2008, 15, 459-486.

48. Kuo, S.W.; Lin, C.L.; Chang, F.C. Phase behavior and hydrogen bonding in ternary polymer blends of phenolic resin/poly(ethylene oxide)/poly(E-caprolactone). Macromolecules 2002, 35, $278-285$.

49. Zhang, H.; Bhagwagar, D.E.; Graf, J.F.; Paitner, P.C.; Coleman, M.M. The effect of hydrogen bonding on the phase behaviour of ternary polymer blends. Polymer 1994, 35, 5379-5397.

50. Chen, W.C.; Kuo, S.W.; Lu, C.H.; Chang, F.C. Self-assembly structures through competitive interactions of crystalline-amorphous diblock copolymer/homopolymer blends: Poly(E-caprolactone-b-4-vinyl pyridine)/Poly(vinyl phenol). Macromolecules 2009, 42, 3580-3590.

51. Zhao, D.; Huo, Q.S.; Feng, J.L.; Chmelka, B.F.; Stucky, G.D. Nonionic triblock and star diblock copolymer and oligomeric surfactant syntheses of highly ordered, hydrothermally stable, mesoporous silica structures. J. Am. Chem. Soc. 1998, 120, 6024-6036.

52. Meng, Y.; Gu, D.; Zhang, F.; Shi, Y.; Cheng, L.; Feng, D.; Wu, Z.; Chen, Z.; Wan, Y.; Stein, A.; Zhao, D. A family of highly ordered mesoporous polymer resin and carbon structures from organic-organic self-assembly. Chem. Mater. 2006, 18, 4447-4464.

53. Harkin, W.D.; Jura, G. Surfaces of solids. XIII. A vapor adsorption method for the determination of the area of a solid without the assumption of a molecular area, and the areas occupied by nitrogen and other molecules on the surface of a solid. J. Am. Chem. Soc. 1944, 66, 1366-1373.

54. Kuo, S.W.; Lin, H.C.; Huang, W.J.; Huang, C.F.; Chang, F.C. Hydrogen bonding interactions and miscibility between phenolic resin and octa(acetoxystyryl) polyhedral oligomeric silsesquioxane (AS-POSS) nanocomposites. J. Polym. Sci. Polym. Phys. 2006, 44, 673-686.

55. Kuo, S.W.; Lin, C.L.; Chang, F.C. The study of hydrogen bonding and miscibility in poly(vinylpyridines) with phenolic resin. Polymer 2002, 43, 3943-3949.

(C) 2013 by the authors; licensee MDPI, Basel, Switzerland. This article is an open access article distributed under the terms and conditions of the Creative Commons Attribution license (http://creativecommons.org/licenses/by/3.0/). 